\title{
The role of Plasminogen Activator Inhibitor 1 in predicting sepsis-associated liver dysfunction: an observational study
}

Ewa Woznica Niesobska ( $\square$ ewa.anna.woznica@gmail.com )

Uniwersytet Medyczny im Piastów Śląskich we Wrocławiu https://orcid.org/0000-0002-6400-9560

\section{Patrycja Lesnik}

Uniwersytet Medyczny im Piastow Slaskich we Wroclawiu

Ryszard Woznica

Wadowice District Hospital

Jaroslaw Janc

4 Wojskowy Szpital Kliniczny z Poliklinika SP ZOZ we Wroclawiu

Malgorzata Zalewska

Uniwersytet Medyczny im Piastow Slaskich we Wroclawiu

\section{Lidia Lysenko}

Uniwersytet Medyczny im Piastow Slaskich we Wroclawiu

\section{Research}

Keywords: sepsis-associated liver dysfunction (SALD), liver failure, plasminogen activator inhibitor 1 (PAI-

1), aspartate transaminase (AST), sepsis

Posted Date: January 7th, 2021

DOl: https://doi.org/10.21203/rs.3.rs-46756/v2

License: (9) This work is licensed under a Creative Commons Attribution 4.0 International License.

Read Full License 


\section{Abstract}

Background: Sepsis-associated liver dysfunction (SALD) is associated with poor prognosis and increased mortality in the Intensive Care Unit. Bilirubin is one of the components of Sequential Organ Failure Assessment used in Sepsis-3 criteria. Hyperbilirubinemia is a late and non-specific symptom of liver dysfunction. The aim of the study was to identify plasma biomarkers, which could be used for the early diagnosis of SALD.

Methods: A single-centre, prospective observational study was conducted in the ICU of Wroclaw University Hospital. Plasma biomarkers - prothrombin time, INR, antithrombin III, bilirubin, aspartate transaminase (AST), alanine transaminase, alkaline phosphatase, gamma glutamyl transferase, albumin, endothelin-1, hepcidin, plasminogen activator inhibitor-1 (PAl-1), thrombin-antithrombin complex and interferon-gamma inducible protein $10 \mathrm{kDa}$ were analysed. Plasma samples were obtained from eligible septic patients within 24 hours after having developed sepsis/septic shock. Enrolled patients were followed for 14 days for developing SALD and 28 days for overall survival.

Results: 79 patients were enrolled in the study, and 24 (30.4\%) of them developed SALD. PAI- 1 with a cutoff value of $9 \mathrm{ng} / \mathrm{ml}$ was shown to be a predictor of SALD (AUC $=0.727$, sensitivity $79.2 \%$; specificity $41.8 \%$; accuracy $53.2 \%$ ) and of 28-day survival in patients with sepsis/septic shock (log rank test, $\mathrm{p}=0.00091)$. This was also useful in predicting 28-day survival, in combination with AST (log rank test, $\mathrm{p}=0.00242$ ).

Conclusions: Sepsis-associated hyperbilirubinemia is frequent, but bilirubin is a late and non-specific marker of SALD. Measuring PAI-1 serum levels at the onset of sepsis/ septic shock may be useful in predicting the development of SALD. A combination of PAI-1 and AST better predicts the 28-day survival than PAI-1 alone, but due to the low cut-off values of AST, this might not be clinically significant.

\section{Introduction}

Sepsis-associated liver dysfunction (SALD) is associated with poor prognosis and increased mortality in Intensive Care Unit (ICU) patients [1]. It remains a key component of multiple organ dysfunction syndrome (MODS) complicating sepsis.

In sepsis, infection combined with the hyperactivity of the inflammatory response and microcirculatory failure contribute to organ dysfunction. In available reports, due to the lack of homogenous diagnostic criteria, the incidence of SALD varies from $1.1 \%$ up to $34.7 \%$ [2]. It may be present as hypoxic hepatitis $(\mathrm{HH})$, sepsis-induced cholestasis and/or coagulopathy [3] and the degree of organ injury may range from mild liver dysfunction to life-threatening liver failure.

According to Sepsis-3 criteria, an acute change in a sequential organ failure assessment (SOFA) score of $\geq 2$ in response to an infection allows life-threatening organ dysfunction defined as sepsis to be diagnosed [4]. An increase in bilirubin serum concentration can be a signal of developing liver 
dysfunction. The elevation of bilirubin concentration in human plasma of $>1.9 \mathrm{mg} / \mathrm{dl}$ gives a SOFA score of 2. Bilirubin itself is a late and non-specific marker of hepatic dysfunction. Hyperbilirubinemia may be caused by hemolysis, cholestasis and hepatic dysfunction of multiple origins: decreased bilirubin transport, uptake and clearance, as well as hepatic ischemia, hepatocellular damage [2].

Acute liver failure (ALF) is defined as an acute liver injury with an onset of hepatic encephalopathy (HE) and an increase in an International Normalised Ratio (INR) of $>1.5$, in patients with no pre-existing liver disease [5]. In an ICU setting, due to multiple possible causes of impaired consciousness, diagnosing HE is difficult. Sepsis induced $\mathrm{HH}$ is a rare cause of ALF, mainly due to organ hypoperfusion. However, an increased blood flow and cardiac output in the primary stages of septic shock might not be enough to compensate for an increased hepatic oxygen demand and also result in the development of $\mathrm{HH}$ [2]. Ischemic/hypoxic hepatitis is reported in up to $2.5 \%$ of all the ICU patients [6].

We postulated that the definition of SALD requires redefining and creating more specific diagnostic criteria. The aim of the study was to identify plasma biomarkers, which can be used for an early diagnosis of SALD.

\section{Materials And Methods}

A single-centre, prospective observational study was conducted in a 14-bed medicosurgical ICU at Wroclaw University Hospital from September 2015 to April 2019. The study was approved by the Bioethics Committee of the Wroclaw Medical University, informed written consent was obtained from all of the patients or their families.

The study enrolled adult patients admitted to the ICU due to sepsis/ septic shock and patients who developed sepsis/septic shock during their ICU stay. Sepsis/ septic shock was defined according to the Sepsis-3 criteria [4]. Exclusion criteria were: age $<18$ years old, pregnancy, pre-existing liver disease (cholestatic disorders; genetic, vascular, metabolic liver diseases; viral hepatitis; liver tumours), liver cirrhosis (Child-Pugh class A, B or C), immunosuppression, HIV infection, cancer and xenobiotics intoxication. Patients with missing data were excluded from the study. All patients were treated according to Surviving Sepsis Guidelines 2012 (patients admitted to the ICU before the publication of new definition and guidelines) and Surviving Sepsis Guidelines $2016[4,7]$.

Once the patient was qualified for the study, clinical and demographic data including: age, sex, comorbidity, Acute Physiology and Chronic Health Evaluation (APACHE II) score, SOFA score and origin of sepsis were recorded in the study protocol. The APACHE II and SOFA scores were subsequently recorded on days 1, 3, 5, 7 and 14. Patients were also screened for the development of Disseminated Intravascular Coagulation (DIC) using ISTH Criteria for DIC on the same days [8].

Plasma biomarkers (prothrombin time, INR, antithrombin III, bilirubin, aspartate transaminase -AST, alanine transaminase - ALT, albumin, alkaline phosphatase - ALP, gamma glutamyl transpherase - GGT) 
were measured within 24 hours after enrolment in the study (day 1) and on days 3, 5, 7, 14. An abdominal ultrasound was performed in order to exclude mechanical causes of hyperbilirubinemia.

At the same time blood samples were drawn for the analysis of novel biomarkers: endothelin-1 (ET-1), hepcidin, plasminogen activator inhibitor 1 (PAI-1), thrombin-antithrombin (TAT) complex and interferongamma inducible protein $10 \mathrm{kDa}(\mathrm{IP}-10)$.

Blood samples were collected and centrifuged at $3000 \mathrm{rpm}$ at room temperature in EDTA tubes, consecutively samples were frozen at -28 Celsius degree within 30 minutes of collection.

Levels of human hepcidin, IP-10, PAI-1, ET-1 were measured using quantikine ELISA tests (R\&D Systems Inc., Minneapolis, MN, USA). Human TAT complex levels were measured using Assay Max (Assaypro LLC, St. Charles, USA). All assays employ the quantitative sandwich enzyme immunoassay technique. Tests were performed and interpreted according to the manufacturer's instructions.

Taking SOFA scoring into consideration, we defined SALD as an acute elevation of the serum bilirubin level of $2 \mathrm{mg} / \mathrm{dl}$ or more, excluding causes of hyperbilirubinemia other than sepsis.

The primary endpoint of the study was the development of SALD, while staying in the ICU. The secondary endpoint was 28-day overall survival.

\section{Analysed biomarkers}

\section{IP-10}

IP-10 is induced in different cells, i.e. leukocytes (neutrophils, monocytes, macrophages), in response to type 1 and 2 interferons (IFN) and lipopolysaccharide (LPS) stimulation. IP-10 induces apoptosis, cell growth inhibition, chemotaxis and angiostasis [9]. IP-10 activates C-X-C motif chemokine receptor 3 (CXCR3), in response to viral infections, autoimmune diseases, allotransplantation and cancer, which is an important regulator of natural killer (NK), natural killer T (NKT) and T helper (Th) 1 lymphocyte trafficking [10]. In the liver, IP-10 is secreted by hepatocytes in areas of lobular inflammation and may be responsible for the development of intrahepatic inflammation. IP-10 is involved in the pathogenesis of hepatitis $\mathrm{C}$ and hepatitis $\mathrm{B}$ and has recently been shown to play a pivotal role in the pathogenesis of experimental steatohepatitis $[11,12,13]$.

\section{ET-1}

Elevated ET-1 plasma levels have been reported in patients with septic shock [14]. ET-1 is a vasoconstrictive molecule synthesised by endothelial cells in response to its injury. It also stimulates phagocytosis and chemotaxis of monocytes/macrophages and neutrophils therefore augmenting the inflammatory response [15]. In a murine model, hepatic macrophages were shown to be the primary source of elevated plasma levels of ET-1 [16]. Hepatic stellate cells, sinusoidal endothelial cells and Kupffer cells are the hepatic source of ET-1. ET-1 being a local regulator of hepatic sinusoidal 
microcirculation, acts via $\mathrm{ET}_{\mathrm{A}} / \mathrm{ET}_{\mathrm{B} 2}$ receptors on hepatic stellate cells, causing liver sinusoid constriction [17]. Endothelin-mediated microcirculatory failure leads to hepatocellular injury via worsening the oxygen delivery and metabolic dysfunction during sepsis [18].

\section{Hepcidin}

Hepcidin is a peptide of mostly hepatic origin involved in iron metabolism. Increased serum hepcidin levels were observed in neoplastic diseases, inflammation and sepsis [19]. Its expression is suppressed by iron deficiency, anaemia, and hypoxia, but induced by iron overload, inflammatory stimuli and LPS [20]. During inflammatory states, hepcidin expression is induced via cytokine IL-6 [21]. The antimicrobial function of hepcidin was shown in several studies, but the mechanism of both antibacterial and antifungal action is not yet well understood [19]. Iron metabolism may be a useful predictor of outcome in patients with liver disease. In the murine N-acetyl-p-amino-phenol (APAP) - induced acute liver failure model, hepcidin was shown to be an independent predictor of mortality [22].

\section{TAT}

TAT, a marker of thrombin generation, forms following the neutralisation of thrombin by antithrombin III (AT III) [23]. AT III is synthesised in the liver and is a natural anticoagulant. Its anti-inflammatory function is due to the neutralisation of thrombin, which is responsible for leukocyte rolling and adhesion, but also it depends on blocking the effect of protease activated receptor-1 [24]. TAT can be used as a sensitive parameter of the latent activation of the clotting pathway. The rise of TAT suggests continuous thrombin generation and antithrombin depletion [25]. In patients with liver cirrhosis, elevated TAT levels are also observed in patients with Child-Pugh A. TAT and AT III are thought to be independently associated with the occurrence of liver dysfunction [26].

\section{PAl-1}

PAl-1 is a principal inhibitor of fibrinolysis. Elevated PAl-1 is linked to sepsis-induced coagulopathy and the development of disseminated intravascular coagulation (DIC). PAl-1 levels correlate with the severity of MODS in sepsis and DIC [27]. The PAl-1 gene is expressed in the liver, endothelial cells, macrophages, adipose tissue, the heart and kidney [28]. An increase in plasma PAI-1 after LPS-stimulation may be a combined effect of both PAI-1 release from activated platelets and its synthesis associated with PAI-1 gene expression on hepatocytes [29]. Plasma PAI-1 levels are also strongly related to liver steatosis, which supports the thesis of the liver being an important source of circulating PAI-1 [30].

\section{Statistical analysis}

Continuous data are presented as median and lower and upper quartiles for non-normally distributed variables or as mean and standard deviation for the normally distributed variables. Statistical differences between the groups were calculated using the non-parametric Mann-Whitney U test. Statistical significance between the frequencies was calculated using the chi-square test. The relation between the 
two parameters was assessed using a correlation analysis and the Spearman correlation coefficients were calculated. Survival curves were obtained using the Kaplan-Meier method and were compared using the log rank test. The multivariate analysis was performed using the Cox proportional hazard regression model. The receiver operating characteristic (ROC) curve analysis was performed to calculate the area under the receiver operating characteristic curve. The best cut-off values were calculated to maximise the Youden index. The positive predictive value (PPV), negative predictive value (NPV) and accuracy (true positive+true negative $/ \mathrm{N}$ ) were also calculated. The $\mathrm{P}$ value of less than 0.05 was required to reject the null hypothesis. Statistical analysis was performed using the EPIINFO Ver. 7.2.3.1 software package.

\section{Results}

During the study period 480 patients were admitted to the ICU due to sepsis / septic shock. According to the study criteria 305 patients were excluded and a further 175 were enrolled into the study. During the observation period 88 patients were excluded, due to causes of hyperbilirubinemia other than sepsis. Another 11 patients were excluded due to an observed increased ALP levels caused by factors other than cholestasis. Finally 79 patients were included into the analysis. The flow of patients is shown on Fig. 1 . Sepsis was diagnosed in 32 (40.5\%) and septic shock in 47 (59.5\%) patients.

Patients were severely ill with a mean APACHE II score of 24. The DIC score according to the ISTH criteria were calculated. None of the patients in the study group developed DIC at any time of observation.

Out of the 79 patients, $24(30.4 \%)$ met the criteria of SALD. None of the patients developing SALD required extracorporeal liver support. Median bilirubin in the SALD group was $2.25(1.1 \div 4.16) \mathrm{mg} / \mathrm{dl} ; 3.3$ $(2.1 \div 5.67) \mathrm{mg} / \mathrm{dl} ; 5.65(2.25 \div 6.95) \mathrm{mg} / \mathrm{dl} ; 5.94(1.9 \div 7.6) \mathrm{mg} / \mathrm{dl} ; 4.4(2.2 \div 5.6) \mathrm{mg} / \mathrm{dl}$ at days $1,3,5,7$ and 14 respectively. At the time of enrolment in the study, there was no difference in the severity of the disease between the groups. The characteristics of the patients is shown in Table 1.

\section{Tab. 1. Patients' characteristics at baseline (day 1).}




\begin{tabular}{|c|c|c|c|c|}
\hline & $\begin{array}{l}\text { All patients } \\
(\mathrm{n}=79)\end{array}$ & $\begin{array}{l}\text { Bilirubin }<2 \mathrm{mg} / \mathrm{dl} \\
\text { (no-SALD) }(\mathrm{n}=55)\end{array}$ & Bilirubin $\geq 2 \mathrm{mg} / \mathrm{dl}(\mathrm{SALD})(\mathrm{n}=24)$ & p-value \\
\hline Age (years) & $63,9 \pm 16,1$ & $67(60 \div 74)$ & $61,0(46,0 \div 78,0)$ & 0,63 \\
\hline Sex (female/male) & $31 / 48$ & $22(40 \%) / 33(60 \%)$ & $9(37,5 \%) / 15(62,5 \%)$ & 0,83 \\
\hline SOFA (min-max) & $10(7 \div 13)$ & $9(7 \div 13)$ & $12(9 \div 14)$ & 0,09 \\
\hline APACHE II & $24(15 \div 30)$ & $24(15 \div 30)$ & $24,5(15,5 \div 28,5)$ & 0,98 \\
\hline Sepsis & 32 & $25(78,1 \%)$ & $7(21,9 \%)$ & 0,18 \\
\hline Septic shock & 47 & $30(63,8 \%)$ & $17(36,2 \%)$ & \\
\hline \multicolumn{5}{|l|}{ Source of sepsis } \\
\hline Abdominal infection (ABD) & $32(40,51 \%)$ & $23(41,82 \%)$ & $9(37,5 \%)$ & 0,91 \\
\hline Pulmonary infection (PNEU) & $27(34,18 \%)$ & $17(30,91 \%)$ & $10(41,67 \%)$ & 0,5 \\
\hline Soft tissue infection (TISS) & $3(3,8 \%)$ & $2(3,64 \%)$ & $1(4,17 \%)$ & 0,99 \\
\hline Neuroinfection (NEUR) & $4(5,06 \%)$ & $3(5,45 \%)$ & $1(4,17 \%)$ & 0,99 \\
\hline Bloodstream infection (BSI) & $3(3,8 \%)$ & 0 & $3(12,5 \%)$ & 0,026 \\
\hline Urinary tract infection (UTI) & $6(7,59 \%)$ & $6(10,91 \%)$ & 0 & 0,17 \\
\hline UTI, PNEU & $1(1,27 \%)$ & $1(1,82 \%)$ & 0 & 0,99 \\
\hline NEUR, BSI & $1(1,27 \%)$ & $1(1,82 \%)$ & 0 & 0,99 \\
\hline PNEU, BSI & $2(2,53 \%)$ & $2(3,64 \%)$ & 0 & 0,99 \\
\hline \multicolumn{5}{|l|}{ Comorbidities } \\
\hline HTA & $37(46,84 \%)$ & $26(47,27 \%)$ & 11 (45,83\%) & 0,89 \\
\hline DM & $23(29,11 \%)$ & 19 (34,55\%) & $4(16,67 \%)$ & 0,18 \\
\hline $\mathrm{CCD}$ & $3(3,8 \%)$ & $1(1,82 \%)$ & $2(8,33 \%)$ & 0,22 \\
\hline $\mathrm{CA}$ & $8(10,13 \%)$ & $6(10,91 \%)$ & $2(8,33 \%)$ & 0,99 \\
\hline OBS & $8(10,13 \%)$ & 5 (9,09\%) & $3(12,5 \%)$ & 0,69 \\
\hline CKD & $18(23,68 \%)$ & $15(27,27 \%)$ & $3(12,5 \%)$ & 0,15 \\
\hline CPD & $10(12,66 \%)$ & $8(14,55 \%)$ & 2 (8,33\%) & 0,72 \\
\hline ARY & $16(20,25 \%)$ & 11 (22\%) & 5 (20,83\%) & 0,99 \\
\hline ALC & $10(12,66 \%)$ & 7 (12,73\%) & $3(12,5 \%)$ & 0,99 \\
\hline NEUR & $4(5,06 \%)$ & $4(7,27 \%)$ & 0 & 0,31 \\
\hline OTH & $8(10,13 \%)$ & $5(9,09 \%)$ & $3(12,5 \%)$ & 0,69 \\
\hline 28-day survival & $49(62 \pm 5,5 \%)$ & $37(67,3 \pm 6,3 \%)$ & $12(50,0 \pm 10,2 \%)$ & 0,12 \\
\hline
\end{tabular}

Data are expressed as mean \pm SD, median (interquartile range), or No. (\%). p-value - comparison of groups with and without SALD. HTA - hypertension arterial, DM - diabetes mellitus, CCD - chronic cardiac disease, CA - cardiac arrest, OBS - obesity, CKD chronic kidney disease, CPD - chronic pulmonary disease, ARY - arrhythmia, ALC - alcoholic disease, NEUR - chronic neurological disease, OTH - other

There was no statistically significant difference in comorbidities between the groups. None of the patients in our study group had metabolic syndrome. In our study group neither alcohol abuse nor obesity had a statistically significant impact on the development of SALD. Apart from bloodstream infections (BSI), there was no difference in the source of sepsis between the groups. There was no case of BSI in 
bilirubin $<2 \mathrm{mg} / \mathrm{dl}$ group. We evaluated the association between plasma biomarkers measured within the first $24 \mathrm{~h}$ after enrolment in the study. The analysed biomarkers were also investigated as predictors for the 28-day survival. The plasma biomarkers levels at the time of enrolment into the study (day 1) are shown in Table 2. AST and ALP were significantly higher in the SALD group, compared to the no-SALD group ( $p=0,0234$ and $p=0.00348$ respectively). What is more, a statistically significant difference between the groups was observed in the PCT levels $-3.99 \mathrm{ng} / \mathrm{ml}(1.69 \div 17.83)$ vs $28.0 \mathrm{ng} / \mathrm{ml}(3.1 \div 71.3), p=0.0135$. Consequently, we decided to analyse novel biomarkers at baseline.

Tab. 2. Plasma biomarkers at baseline (day 1).

\begin{tabular}{|c|c|c|c|c|c|c|}
\hline & $\begin{array}{l}\text { Normal } \\
\text { values }\end{array}$ & $\begin{array}{l}\text { All } \\
(n=79)\end{array}$ & $\begin{array}{l}\text { Bilirubin }<2 \mathrm{mg} / \mathrm{dl} \\
(\mathrm{n}=55)\end{array}$ & $\begin{array}{l}\text { Bilirubin } \\
(n=24)\end{array}$ & (SALD) & p-value \\
\hline \multicolumn{7}{|c|}{ Routinely measured biomarkers } \\
\hline AST (U/l) & $5-34$ & $590,6 \pm 1970,8$ & $51(29 \div 155)$ & $124(38 \div 325)$ & & 0,02 \\
\hline $\mathrm{ALT}(\mathrm{U} / \mathrm{l})$ & $0-55$ & $310,9 \pm 1109,7$ & $46(20 \div 81)$ & $61,5(27 \div 102)$ & & 0,16 \\
\hline Albumin (g/dl) & $3,2-4,6$ & $2,34 \pm 0,515$ & $2,35(2,0 \div 2,65)$ & $2,3(1,8 \div 2,7)$ & & 0,85 \\
\hline AT III (\%) & $80-120$ & $58,8 \pm 20,2$ & $58,5(45 \div 81,1)$ & $53,3(41,3 \div 61,3)$ & & 0,08 \\
\hline INR & $0,9-1,3$ & $1,45 \pm 0,64$ & $1,26(1,12 \div 1,45)$ & $1,35(1,16 \div 1,83)$ & & 0,13 \\
\hline $\begin{array}{l}\text { Prothrombin ratio } \\
(\%)\end{array}$ & $80-114$ & $73,9 \pm 19,8$ & $79,7(66,6 \div 87,8)$ & $73,7(55,8 \div 86,3)$ & & 0,27 \\
\hline APTT (s) & $21-30,1$ & $42,7 \pm 16,3$ & $36,9(30,9 \div 46,7)$ & $44,3(33,9 \div 53,6)$ & & 0,09 \\
\hline GGT (IU/l) & $<40$ & $166,8 \pm 342,4$ & $74,0(20,0 \div 97,0)$ & $87,0(20,0 \div 231,0)$ & & 0,427 \\
\hline $\operatorname{ALP}(\mathrm{U} / \mathrm{l})$ & $40-120$ & $137,7 \pm 168,0$ & $75,0(54,0 \div 148,0)$ & $147,5(94,0 \div 206,0)$ & & 0,00348 \\
\hline Thrombocytes (/mcl) & $150-400$ & $225,6 \pm 107,9$ & $\begin{array}{l}224,0 \\
(161,0 \div 309,0)\end{array}$ & $206,5(133,5 \div 250,5)$ & & 0,121 \\
\hline Creatinine (mg/dl) & $0,6-1,3$ & $2,00 \pm 1,71$ & $1,70(0,87 \div 2,45)$ & $1,48(0,92 \div 2,04)$ & & 0,707 \\
\hline PCT (ng/ml) & $0,05-0,1$ & $38,6 \pm 108,1$ & $3,99(1,69 \div 17,83)$ & $28,0(3,1 \div 71,3)$ & & 0,0135 \\
\hline $\mathrm{CRP}$ (mg/dl) & $<5$ & $234,5 \pm 116,6$ & $\begin{array}{l}239,8 \\
(141,8 \div 322,9)\end{array}$ & $247,2(155,0 \div 318,0)$ & & 0,444 \\
\hline
\end{tabular}

\section{Novel biomarkers}

\begin{tabular}{lllll} 
IP-10 $(\mathrm{pg} / \mathrm{ml})$ & $47-382$ & $932,7 \pm 1643,5$ & $\begin{array}{l}321,9 \\
(198,7 \div 796,9)\end{array}$ & $315,4(140,7 \div 961,1)$ \\
\hline ET-1 $(\mathrm{pg} / \mathrm{ml})$ & $0,58-1,96$ & $2,06 \pm 1,60$ & $1,72(1,19 \div 2,45)$ & $1,54(1,06 \div 2,39)$ \\
\hline PAI-1 $(\mathrm{ng} / \mathrm{ml})$ & $0,99-16,9$ & $38,3 \pm 53,3$ & $13,1(6,5 \div 29,9)$ & $51,6(9,9 \div 74,9)$ \\
\hline TAT $(\mathrm{ng} / \mathrm{ml})$ & $0,5-10$ & $21,3 \pm 116,6$ & $4,3(2,6 \div 6,5)$ & $3,75(2,83 \div 5,75)$ \\
\hline Hepcidin $(\mathrm{ng} / \mathrm{ml})$ & $82,4-56700$ & $221,8 \pm 167,1$ & $195(101,1 \div 321,9)$ & $158,2(93,5 \div 217,9)$
\end{tabular}

Data are expressed as mean \pm SD, median (interquartile range), or No. (\%). p-value - comparison of groups with and without SALD

At baseline we observed a statistically significant difference between the groups only for PAl-1. In the group with no SALD the levels of PAI-1 were significantly lower than in patients with SALD. Subsequently, a ROC curve analysis for PAI-1 was conducted (Fig. 2). 
The PAl-1 cut-off was calculated for a maximal value of the Youden index (0.21). PAl-1 values of $>=9 \mathrm{ng} / \mathrm{ml}$ can be a predictor of SALD, with a sensitivity of $79.2 \%$, specificity of $41.8 \%$ and PPV $-37.3 \%$, NPV $-82.1 \%$ (accuracy of $53.2 \%$ ).

The Spearman correlation was conducted between PAI-1 and CRP, PCT and the platelet count. No statically significant correlation was observed between PAI-1 and CRP $(R=-0.21 ; p=0.0787), P C T(R=0.21$; $p=0.0687)$ or the platelet count $(R=-0.13 ; p=0.265)$.

We postulated that at baseline bilirubin is not a good predictor of 28-day survival in patients with sepsis/ septic shock (log rank test, $\mathrm{p}=0.117$ ). On the contrary, what is shown on Figure 3., PAl-1 seems to be a good predictor of 28-day survival in patients with sepsis/septic shock (log rank test, $p=0.00091)$. AST alone with a cut-off value of $70 \mathrm{U} / \mathrm{l}$ is not a good predictor of survival (log rank test, $\mathrm{p}=0.0797$; specificity $65.2 \%$, sensitivity $68.6 \%$, PPV $48.4 \%$, NPV $81.4 \%$, accuracy $67.6 \%$ ), but in combination with PAl-1 it improves its strength of 28-day ICU survival prediction (log-rank test, $p=0.00242$; specificity $64.7 \%$; sensitivity $73.9 \%$, PPV $48.6 \%$, NPV $84.6 \%$, accuracy $67.6 \%$ ).

There was no statistically significant difference between the groups in the severity of the disease (APACHE II score 24 vs. 24.5, p=0.979). A multivariate analysis with the use of the Cox PH model has shown that only PAI-1 and APACHE II scores $>21$ were independent predictors of mortality in the SALD group (Chi2=23.2132, $\mathrm{p}=0.00001)$.

The Spearman correlation was conducted between IP-10, ET-1, PAI-1, hepcidin, TAT on day 1, and bilirubin in consecutive days $3,5,7$ and 14. A statistically significant positive correlation was observed between PAI- 1 on day 1 and bilirubin in the following days: $3,5,7$ (respectively: day 3. $R=0.43, p=0.00028$; day 5 . $R=0.46, p=0.00052$; day $7 . R=0.43, p=0.00258$ ). A statistically significant negative correlation was observed between hepcidin on day 1 and bilirubin in the following days: 5,7 , and 14. (respectively: day 5 . $R=-0.29, p=0.0329$; day 7. $R=-0.32, p=0.0244$, day 14 . $R=-0.60, p=0.0603$ ).

The Spearman correlation was also conducted between IP-10, ET-1, PAI-1, hepcidin and TAT on day 1 and APACHE II and SOFA scores. There was a statistically significant positive correlation between PAI- 1 and SOFA $(R=0,26, p=0,0198)$, but no correlation between hepcidin, IP-10, ET-1, TAT and SOFA or APACHE II scores, as well as no correlation between PAI-1 and APACHE II.

Figure 4. shows median novel biomarkers values on days $1,3,5,7$ and 14 . There is statistically significant difference between the groups in median values of endothelin- $1(p=0.0279)$, PAl- $1(p=0.0111)$ and hepcidin $(p=0.00194)$, but no difference in IP-10 $(p=0.523)$ and TAT $(p=0.522)$ values on day 3 . There is a statistically significant difference in PAI- $1(p=0.00432)$ and TAT $(p=0.0420)$ values between the groups on day 5 , but no difference in IP-10 ( $p=0.0795)$, endothelin- $1(p=0.0761)$ and hepcidin $(p=0.0558)$. The statistically significant difference remains up to day 7 , for PAI- 1 and TAT with $p=0.00942$ and $p=0.0414$ respectively. There is no difference between the groups in median values of biomarkers on day 14. 


\section{Discussion}

The results of our study show that almost one third of septic patients had an acute elevation of bilirubin up to $2 \mathrm{mg} / \mathrm{dl}$ or more. The results are consistent with available reports [1]. Two thirds of the enrolled patients fulfilled our SALD criteria within 24 hours of diagnosing sepsis/ septic shock.

After analysing our study group demographics, we demonstrate that, apart from BSI, the cause of sepsis, or comorbidities did not contribute to SALD development.

Interestingly, there was no difference in the severity of the disease (APACHE II score) or the degree of organ dysfunction (SOFA score) at the time of inclusion in patients who developed SALD and those who did not. This suggests that hyperbilirubinemia may just be a signal of worsening liver function, which contributes to adverse outcomes via independent pathways (not included in APACHE II scoring) or that the serum bilirubin cut-off value of $2 \mathrm{mg} / \mathrm{dl}$ is too low to identify patients with an adverse outcome. This is reflected in the results of our study. Mild elevations in bilirubin levels, consequently the degree of organ dysfunction, wasn't severe enough to cause a difference in mortality between the groups. What is more, there is a wide range of other causes influencing mortality in sepsis/septic shock, than hyperbilirubinemia itself. This is also confirmed by the fact, that there was no difference in APACHE II scoring between our study groups.

Bilirubin as a single biomarker is a poor factor in distinguishing newly developing organ dysfunction from a pre-existing one. Due to its late increase and low specificity, finding a single cause of hyperbilirubinemia in ICU patients remains a challenge.

Contrary to Patel et al.[31], in our study, bilirubin was shown to be a poor predictor of survival in septic patients.

Our study was the first to evaluate the correlation between PAl-1 and liver function in septic patients. Out of five analysed biomarkers, only PAI- 1 at the time of enrolment could be useful to predict the development of SALD. In various studies the liver has been proven to be an important source of circulating PAI-1 $[28,30]$. PAI-1 can be a better marker than bilirubin, predicting organ dysfunction, as a correlation between PAI-1 and SOFA scores was shown. The study revealed that the cut-off value for PAl-1 of $9 \mathrm{ng} / \mathrm{ml}$ was subsequent with an acute increase in bilirubin levels of $2 \mathrm{mg} / \mathrm{dl}$ or more. Interestingly, this cut-off value holds within the normal limits $(0.99-16.9 \mathrm{ng} / \mathrm{ml})$. There were also individuals reaching higher PAl-1 levels than the calculated cut-off value of $9 \mathrm{ng} / \mathrm{ml}$ in the no-SALD group. PAl-1 was analysed as a predictive marker, meaning that not all the subjects above the cut-off value develop a liver dysfunction. There must be other risk factors influencing the development of SALD, which requires further investigation. Metabolic syndrome, obesity and alcohol intake are known risk factors increasing the probability of acute liver damage [32]. None of the patients in our study group had metabolic syndrome. Alcohol abuse or obesity did not influence the development of SALD. 
Interestingly, significantly higher levels of PCT were observed in the SALD group compared to the noSALD group (3.99 vs $28.0 \mathrm{ng} / \mathrm{ml}$ ). Even though there was no correlation between PAl-1 and PCT in our study group, it has been shown in an in vitro study on a human hepatocyte model that high concentrations of procalcitonin might impair the hepatocytes function and lead to liver injury [33, 34]. This requires further investigation.

Our results have shown the low specificity of PAI-1 with a high negative predictive value. The low specificity of PAl-1 may be a result of many origins and different factors inducing its synthesis. An increase in plasma PAI-1 after LPS-stimulation may be a combined effect of both the PAl-1 release from activated platelets and its synthesis associated with PAl-1 gene expression on hepatocytes [29]. The results obtained in our study group may indicate that the activated platelets could play a greater role in the increase in PAI-1 levels, than its hepatic source does.

Other authors have investigated PAI-1 as a biomarker of sepsis and DIC. Koyama et al. [35] investigated PAI-1 combined with TAT and protein $\mathrm{C}$ as predictors for the development of overt DIC. In our cohort none of the patients developed DIC, so it was impossible to confront these results with ours. The incidence of DIC in septic patients, diagnosed with ISTH criteria, is reported to be approximately $29 \%$ [36]. The authors think that the cause of the lack of overt DIC in the study group was a result of the used inclusion criteria resulting in choosing only 79 out of $480(28.9 \%)$ septic patients treated in our ICU. In terms of survival, Koyama's [35] results were compatible with ours, confirming PAl-1to be a predictor of survival in septic patients. What is more, the PAI- 1 and APACHE II score above 21 were shown to be independent predictors of mortality. Higher PAI-1 levels were related to higher SOFA scoring at the onset of sepsis, but there was no reflection in APACHE II scoring at the time of inclusion.

We also evaluated PAl-1 in combination with AST as a predictor of 28-day survival. AST and ALT are the markers of hepatocellular integrity. However AST is a sensitive marker of liver cell injury, its specificity remains questionable. Apart from the liver it can be found in cardiac muscle, skeletal muscle, kidneys, brain, pancreas, lungs, leukocyte and erythrocytes. AST levels usually peak before ALT, especially in ischemic or toxic liver injury. Acinar zone 3 is vulnerable to hypoxic damage and the enzyme is mostly distributed in the peripheral site of the acinus [37]. This was confirmed in our study, as the levels of AST at day 1 were significantly higher in the SALD group. This may also indicate ischemic damage as one of the causes of SALD. Moreover, higher levels of ALP in the SALD group indicate that cholestasis might be another presentation of septic liver dysfunction, especially as the authors have excluded patients with increased levels of ALP due to causes other than sepsis induced cholestasis from analysis.

Low cut-off AST values presented in our study are again proof that liver dysfunction in our study group wasn't severe (sepsis-induced cholestasis usually presents as milder condition than hypoxic hepatitis), and the cut-off bilirubin of $2 \mathrm{mg} / \mathrm{dl}$ was too low of a value to diagnose SALD with a potential adverse outcome.

Our analysis revealed that a combination of PAI-1 and AST better predicts 28-day survival than PAI-1 alone, but due to the low cut-off values of AST this might not be clinically significant. 
The analysis of further days of the observation showed that PAl-1 remained higher during the first week of observation in the group of patients who developed SALD. Higher PAl-1 values observed on day 1 were related to a greater increase in bilirubin levels on days 3,5 and 7 , which confirms a potential usefulness of the marker as a predictor of liver dysfunction.

Lower hepcidin values observed on day 1 were related to a greater increase in bilirubin levels on days 5,7 and 14. ET-1 and hepcidin on day 3 and TAT on day 5, could be taken into consideration as predictors of SALD, as their difference between the SALD and no-SALD group remained significant, but our study group was too small to conduct further analysis.

The limitations of the study were: it was a single-centre study and the number of patients enrolled into the study was relatively small; although our results (SALD incidence) matched those demonstrated in previous studies [1]. The lack of generally accepted SALD definition remained a challenge.

PAI-1 may be a marker prognosing SALD, but due to its low specificity and high negative predictive value, it has to be analysed in combination with other markers. AST levels at the time of admission might be a good choice. Further studies are needed to find a unique biomarker of SALD, but firstly to broaden knowledge on its pathophysiology and to find a unanimous definition and define clear diagnostic criteria.

\section{Conclusions}

Sepsis-associated hyperbilirubinemia is frequent, but bilirubin is a late and non-specific marker of SALD. Measuring PAI-1 serum levels at the onset of sepsis/septic shock may be useful in predicting the development of SALD. A combination of PAI-1 and AST better predicts 28-day survival than PAl-1 alone, but due to the low cut-off values of AST, this might not be clinically significant. Very subtle, but still significant differences and low cut off values of the markers prove the authors' hypothesis that a cut-off value of bilirubin $\geq 2 \mathrm{mg} / \mathrm{dl}$ is too low, and higher cut-off values of bilirubin or combination of bilirubin with other markers of liver injury, might be needed to distinguish a group of patients with SALD leading to an adverse outcome.

\section{Declarations}

\section{ETHICS APPROVAL AND CONSENT TO PARTICIPATE}

The study was approved by the Bioethics Committee of Wroclaw Medical University (KB 415/2015; KB 670/2017). Informed consent was obtained from all patients or their families.

\section{CONSENT FOR PUBLICATION}

NOT APPLICABLE

\section{AVAILABILITY OF DATA AND MATERIALS}


The datasets used and/or analysed during the current study are available from the corresponding author on reasonable request.

\section{COMPETING INTERESTS}

The authors declare that they have no competing interests.

\section{FUNDING}

The study was financed by the Polish Ministry of Science and Higher Education as the Diamond Grant project (Project No DI2014 011144).

The publication was prepared under the project financed from the funds granted by the Ministry of Science and Higher Education in the "Regional Initiative of Excellence” programme for the years 20192022, project number 016/RID/2018/19, the amount of funding 11998121,30 PLN.

\section{AUTHORS' CONTRIBUTIONS}

All authors contributed to the study conception and design. Material preparation was performed by EWN, PL and LL. Data collection and analysis were performed by EWN, PL, JJ, RW and LL. Biomarkers assay was made by MZ. The first draft of the manuscript was written by EWN and all authors commented on previous versions of the manuscript. All authors read and approved the final manuscript.

\section{ACKNOWLEDGMENTS}

NOT APPLICABLE

\section{References}

[1] Kobashi H, Toshimori J, Yamamoto K. Sepsis-associated liver injury: Incidence, classification and the clinical significance. Hepatol Res 2013, 43(3):255-66. doi: 10.1111/j.1872-034X.2012.01069.x

[2] Woznica E, Inglot M, Woznica R, Lysenko L. Liver dysfunction in sepsis. Adv Clin Exp Med 2018, 27(4):547-551. doi: 10.17219/acem/68363

[3] Wang D, Yin Y, Yao Y. Advances in sepsis-associated liver dysfunction. Burn Trauma 2014, 2:97-105. doi: 10.4103/2321-3868.132689.

[4] Singer M, Deutschman CS, Seymour WC et al. The third international consensus definitions for sepsis and septic shock (sepsis-3). JAMA 2016, 315(8):801-810. doi:10.1001/jama.2016.0287.

[5] Lee WM, Stravitz RT, Larson AM. Introduction to the revised American Association for the Study of Liver Diseases Position Paper on acute liver failure 2011. Hepatology, 2012;55(3):965-967. doi: 10.1002/hep.25551. 
[6] Tapper EB, Sengupta N, Bonder A. The incidence and outcomes of ichemic hepatits: a systematic review and metaanalisis. AM J Med, 2015;128(12):1314-1321.doi: 10.1016/j.amjmed.2015.07.033.

[7] Dellinger RP, Levy MM, Rhodes A, Annane D et al. Surviving sepsis campaign: international guidelines for management of severe sepsis and septic shock: 2012. Crit Care Med 2013, 41(2):580-637. doi:

10.1097/CCM.0b013e31827e83af.

[8] Taylor FB Jr, Toh CH, Hoots WK, Wada H, Levi M;Scientific Subcommittee on Disseminated Intravascular Coagulation (DIC) of the International Society on Thrombosis and Haemostasis (ISTH). Towards definition, clinical and laboratory criteria, and a scoring system for disseminated intravascular coagulation. Thromb Haemost 2001, 86(5):1327-1330.

[9] Liu M, Guo S, Hibbert JM, Jain V, Singh N, Wilson ON, Stiles JK. CXCL10/IP-10 in Infectious Diseases Pathogenesis and Potential Therapeutic Implications. Cytokine Growth Factor Rev 2011, 22(3):121-130. doi:10.1016/j.cytogfr.2011.06.001.

[10] Herzig SD, Luan L, Bohannon JK, Toliver-Kinsky TE, Guo Y, Sherwood ER. The role of CXCL10 in the pathogenesis of experimental septic shock. Crit Care 2014, 18:R113. doi:10.1186/cc13902

[11] Zhang X, Shen J, Man K, Chu E, Yau TO, Sung J, Go M, Deng J, Lu L, Wong V, SungJ, Farrell G, Yu J. CXCL10 plays a key role as an inflammatory mediator and anon-invasive biomarker of non-alcoholic steatohepatitis. J Hepatol 2014, 61(6):1365-75. doi: 10.1016/j.jhep.2014.07.006.

[12] Abe T, Fukuhara T, Wen X, Ninomiya A, Moriishi K, Maehara Y, Takeuchi O, Kawai T, Akira S, Matsuura Y. CD44 participates in IP-10 induction in cells in which hepatitis $C$ virus RNA is replicating, through an interaction with Toll-like receptor 2 and hyaluronan. J Virol 2012, 86:6159-6170. doi:10.1128/JVI.0687211

[13] Zhou Y, Wang S, Ma JW, Lei Z, Zhu HF, Lei P, Zho-Shun Y, Zhang B, Yao XX, Shi C, Sun LF, Wu XW, Ning Q, Shen GX, Huang B. Hepatitis B virus protein Xinduced expression of the CXC chemokine IP-10 is mediated through activation of NF-kappaB and increases migration of leukocytes. J Biol Chem 2010, 285:12159-12168. doi:10.1074/jbc.M109.067629.

[14] Piechota M, Banach M, Irzmanski R, Barylski M, Piechota-Urbanska M, Kowalski J, Pawlicki L. Plasma Endothelin-1 Levels in Septic Patients. J Intensive Care Med 2007, 22: 232.

[15] Kleniewska P, Piechota-Polanczyk A, Michalski L, Michalska M, Balcerczak E, Zebrowska M, Goraca A. Influence of Block of NF-Kappa B Signaling Pathway on Oxidative Stress in the Liver Homogenates. Oxid Med Cell Longev 2013, 2013: 308358. doi: 10.1155/2013/308358.

[16] McKenna S, Gossling M, Bugarini A, Hill E, Anderson AL, Rancourt RC, Balasubramaniyan N, El Kasmi $\mathrm{KC}$, Wright $\mathrm{CJ}$. Endotoxemia induces IKBß/NFKB dependent ET-1 expression in hepatic macrophages. $J$ Immunol 2015, 195(8): 3866-3879. doi:10.4049/jimmunol.1501017. 
[17] Reynaert H, Thompson MG, Thomas T, Geerts A. Hepatic stellate cells: role in microcirculation and pathophysiology of portal hypertension. Gut 2002, 50(4): 571-581. doi:10.1136/gut.50.4.571

[18] Baveja R, Yokoyama Y, Korneszczuk K, Zhang JX, Clemens MG. Endothelin-1 impairs oxygen delivery in livers from LPS-primed animals. SHOCK 2002, 17(5):383-388, 2002.

[19] Kali A, Charles MV, Seetharam RS. Hepcidin - A novel biomarker with changing trends. Pharmacogn Rev 2015, 9(17): 35-40. doi: 10.4103/0973-7847.156333.

[20] Sangkhae V, Nemeth E. Regulation of the iron homeostatic hormone hepcidin. Adv Nutr 2017, 8(1):126-136. doi: 10.3945/an.116.013961.

[21] Michels K, Nemeth E, Ganz T, Mehrad B. Hepcidin and Host Defense against Infectious Diseases. PLOS Pathogens 2015, 11(8): e1004998. doi:10.1371/journal.ppat.1004998

[22] Spivak I, Arora J, Meinzer C, Durkalski-Mauldin V, Lee MW, Trautwein C, Fontana RJ, Strnad P, Acute Liver Failure Study Group (ALFSG). Low serum hepcidin is associated with reduced short-term survival in adults with acute liver failure. Hepatology 2019, 69(5):2136-2149. doi: 10.1002/hep.30486.

[23] Hoppensteadt D, Tsuruta K, Cunanan J, Hirman J, Kaul I, Osawa Y, Fareed J. Thrombin generation mediators and markers in sepsis-associated coagulopathy and their modulation by recombinant thrombomodulin. Clin Appl Thromb Hemost 2014, 20(2):129-35. doi: 10.1177/1076029613492875.

[24] Toshiaki Iba, Daizoh Saitoh. Efficacy of antithrombin in preclinical and clinical applications for sepsis-associated disseminated intravascular coagulation. J Intensive Care 2014, 2(1):66. doi:

10.1186/s40560-014-0051-6.

[25] Pelzer H, Schwarz A, Heimburger N. Determination of human thrombin-antithrombin III complex in plasma with an enzyme-linked immunosorbent assay. Thromb Haemost 1988, 59:101-6.

[26] Kalambokis GN, Oikonomou A, Baltayiannis G, Christou L, Kolaitis NI, Tsianos EV. Thrombin generation measured as thrombin-antithrombin complexes predicts clinical outcomes in patients with cirrhosis. Hepatol Res 2016, 46(3):E36-44. doi: 10.1111/hepr.12520.

[27] Hack CE. Fibrinolysis in disseminated intravascular coagulation. Semin Thromb Hemost 2001, 27:633-8.

[28] Dimova EY, Kietzmann T. Metabolic, hormonal and environmental regulation of plasminogen activator inhibitor-1 (PAl-1) expression: Lessons from the liver. Thromb Haemost 2008, 100:992-1006.

[29] Ohkura N, Oishi K, Nakakuki Y. Lipopolysaccharide-induced plasma PAI-1 increase does not correlate with PAl-1 synthesised de novo in the liver. Thrombosis Research 2013, 132(3):398-399.

doi.org/10.1016/j.thromres.2013.06.008 
[30] Imagawa S, Fujii S, Dong J, Furumoto T, Kaneko T, Zaman T, Satoh Y, Tsutsui H, Sobel BE. Hepatocyte Growth Factor Regulates E Box-Dependent Plasminogen Activator Inhibitor Type 1 Gene Expression in HepG2 Liver Cells. Arterioscler Thromb Vasc Biol 2006, 26:2407-2413. doi:

10.1161/01.ATV.0000240318.61359.e3.

[31] Patel JJ, Taneja A, Niccum D, Kumar G, Jacobs E, Nanchal R. The association of serum bilirubin levels on the outcomes of severe sepsis. J Intensive Care Med 2015, 30(1):23-9. doi:

$10.1177 / 0885066613488739$.

[32] Canbay A, Tacke F, Hadem J, Trautwein C, Gerken G, Manns MP. Acute Liver Failure. Dtsch Arztebl Int 2011, 108(42): 714-720.

[33] Sauer M, Do. S, Ehler J, et al. Procalcitonin impairs liver cell viability and function in vitro: a potential new mechanism of liver dysfunction and failure during sepsis? Biomed Res Int. 2017; 2017: 6130725, doi: $10.1155 / 2017 / 6130725$.

[34] Woznica E, Lysenko L. Procalcitonin in liver dysfunction - Dr Jekyll or Mr Hyde? Anaesthesiol Intensive Ther 2018, 50 (3), 226-229.

[35] Koyama K, Madoiwa S, Nunomiya S, Koinuma T, Wada M, Sakata A, Ohmori T, Mimuro J, Sakata Y. Combination of thrombin-antithrombin complex, plasminogen activator inhibitor-1, and protein $\mathrm{C}$ activity for early identification of severe coagulopathy in initial phase of sepsis: a prospective observational study. Crit Care 2014, 18(1):R13. doi: 10.1186/cc13190.

[36] Saito S, Uchino S, Hayakawa M, Yamakawa K, Kudo D, lizuka Y et al. Epidemiology of disseminated intravascular coagulation in sepsis and validation of scoring systems. J Crit Care 2019,50:23-30. doi: 10.1016/j.jcrc.2018.11.009.

\section{Figures}




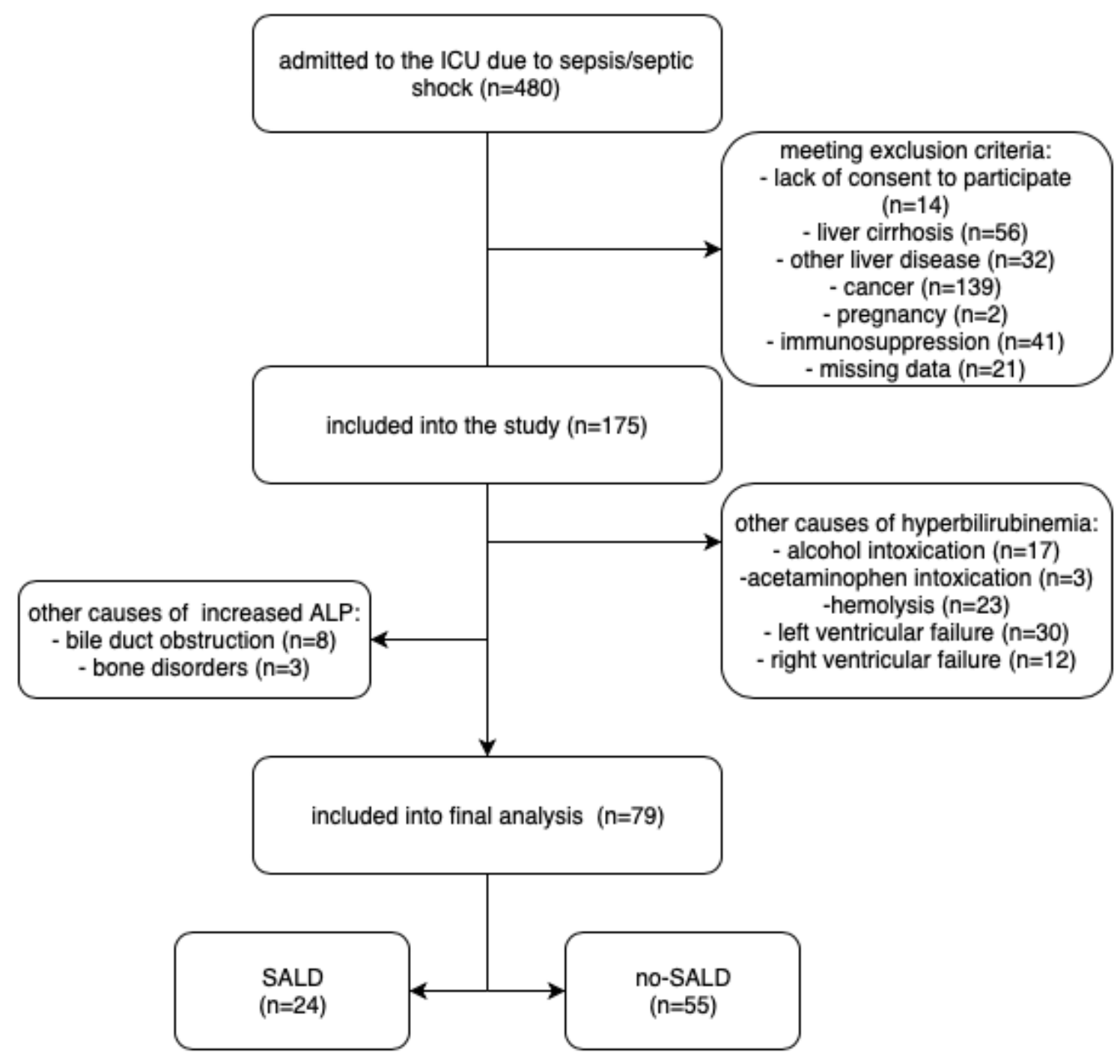

\section{Figure 1}

Flow of the patients included in the study. 


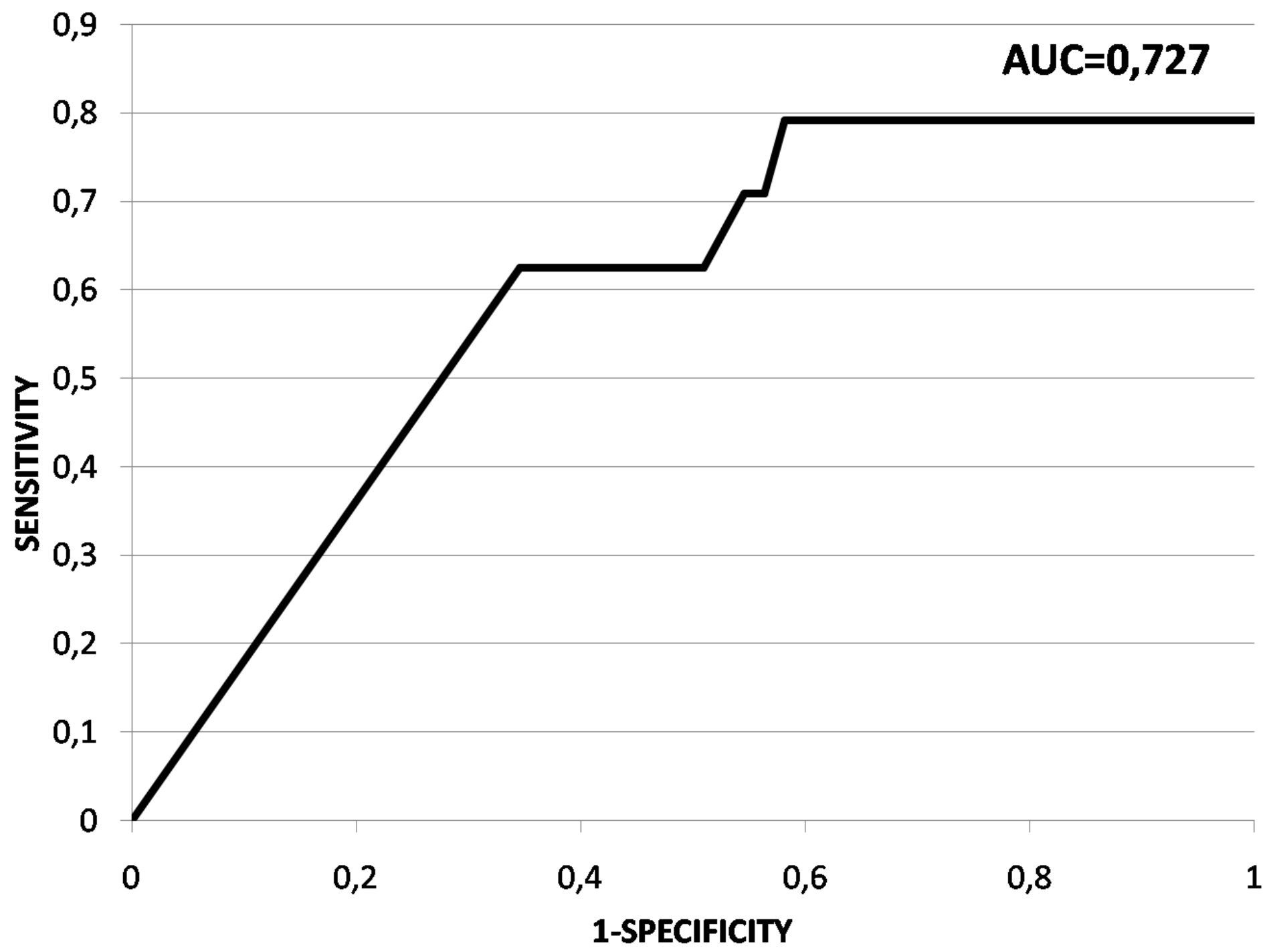

Figure 2

PAI-1 ROC curve for the prediction of SALD. 

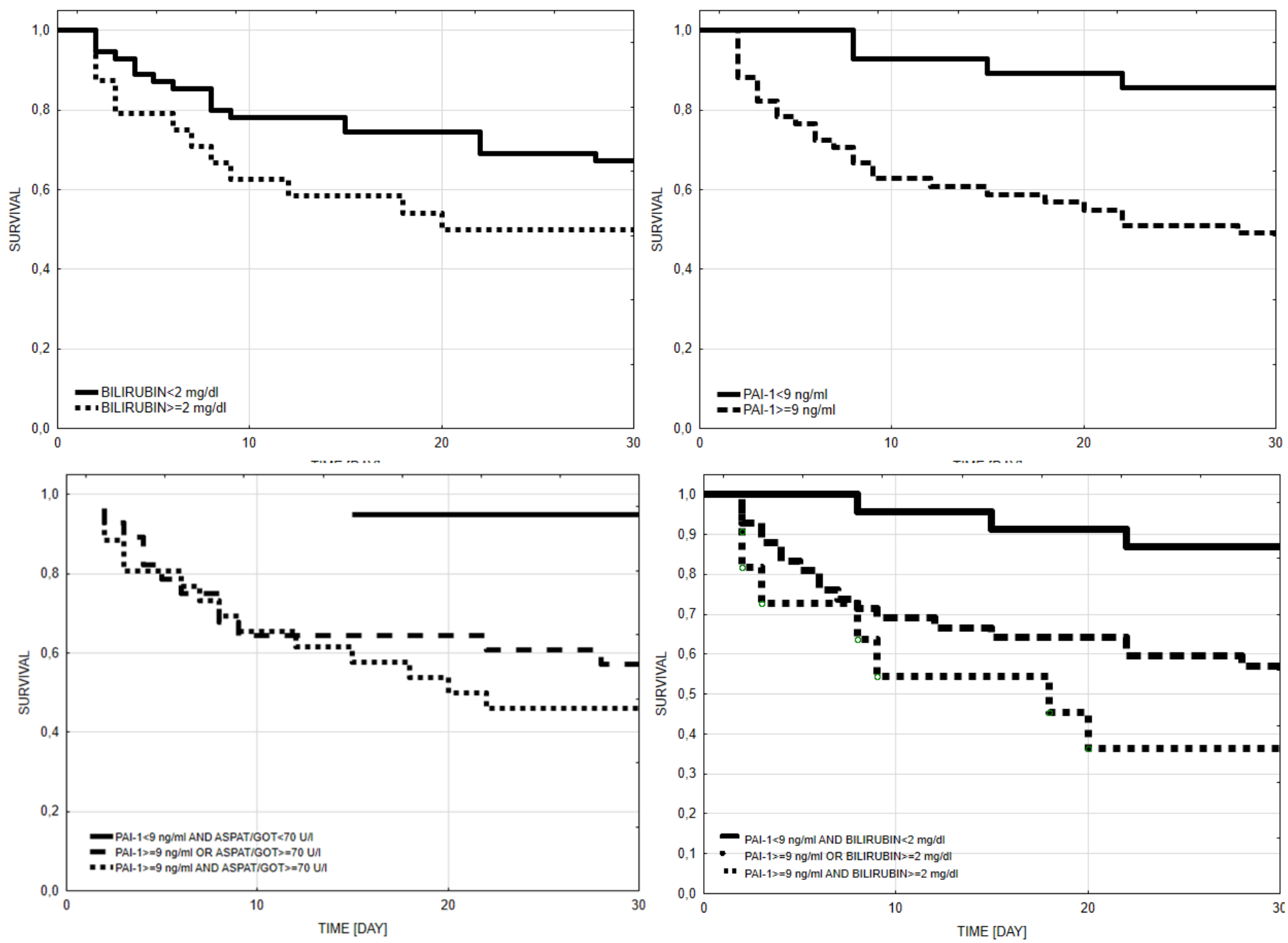

Figure 3

Kaplan-Meier survival curves for bilirubin (Log rank test $p=0.117$ ), PAl-1 (log rank test, $p=0.00091$ ), PAI1+bilirubin (log rank test, $\mathrm{p}=0.00524)$ and PAI-1+AST (log rank test, $\mathrm{p}=0.00242)$. 


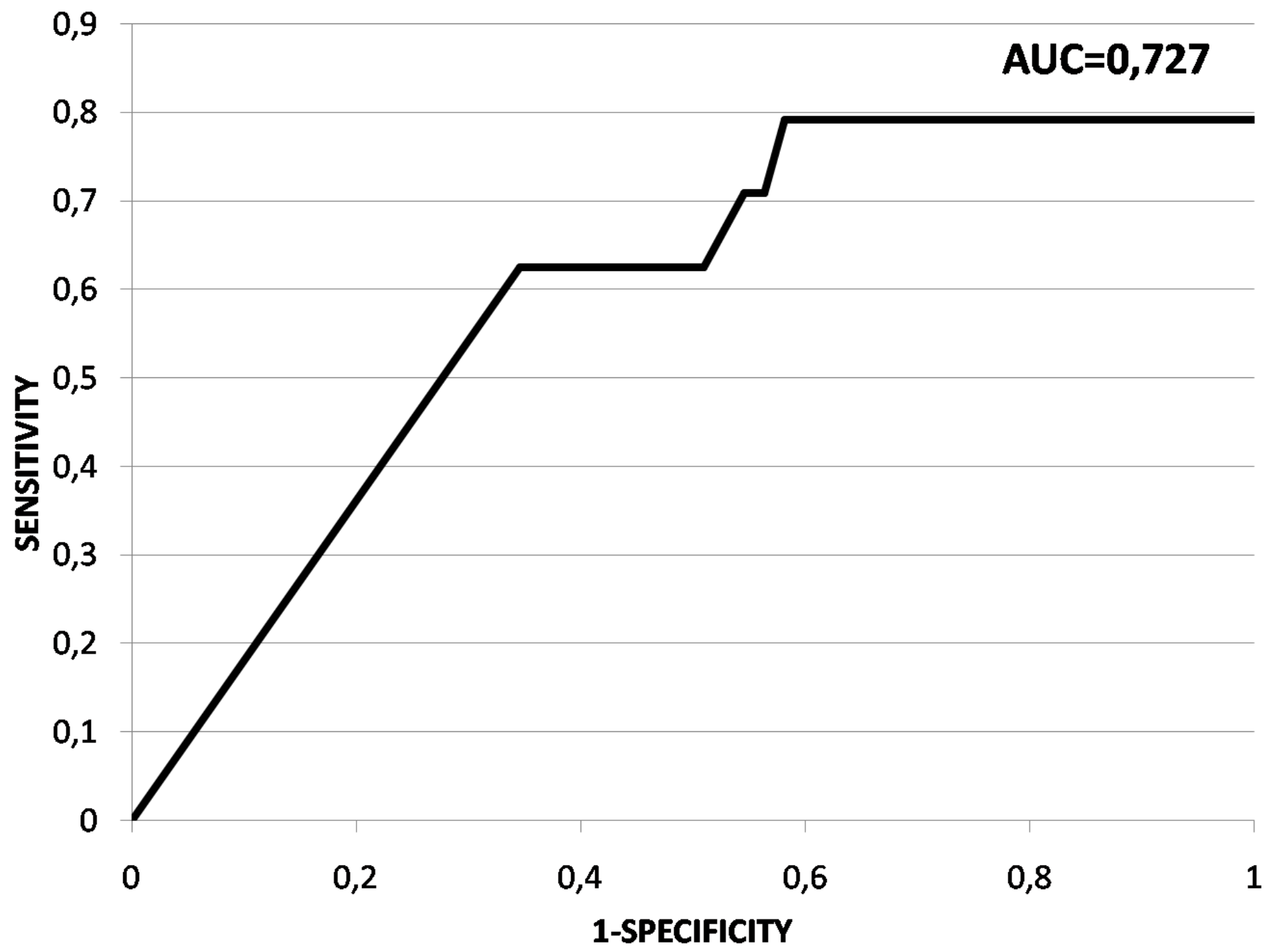

Figure 4

PAl-1 ROC curve for the prediction of SALD. 